Available online at http://jddtonline.info RESEARCHARTICLE

\title{
COMPARATIVE EFFECT OF BETA BLOCKERS AND ANGIOTENSIVE RECEPTOR BLOCKERS ON BLOOD GLUCOSE LEVEL IN HYPERTENSIVE PATIENTS IN UNIVERSITY HOSPITAL
}

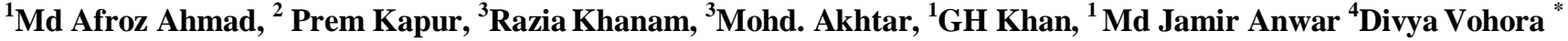 \\ ${ }^{1}$ Research Scholar, Department of Pharmacology, Faculty of Pharmacy, Jamia Hamdard, New Delhi, India \\ ${ }^{2}$ Consultant Physician, Majeedia Hospital, Jamia Hamdard, New Delhi,India \\ ${ }^{3}$ Assistant Professor, Department of Pharmacology, Faculty of Pharmacy, Jamia Hamdard, New Delhi, India \\ ${ }^{4}$ Associate Professor, Department of Pharmacology, Faculty of Pharmacy, Jamia Hamdard, New Delhi, India \\ *Corresponding Author's E-mail: divyavohora@hotmail.com
}

\begin{abstract}
:
Objective: There is highly co-incidence between hypertension and insulin resistance which is the important causative factor to develop diabetes mellitus (DM). There is paucity of data to establish the effect of beta-blockers and ARB on blood glucose level in Indian population. Therefore the present study was planned to search so that confederation among Indian population in a teaching hospital.

Methods: The research study was carried out in 85 hypertensive patients without diabetes visiting the OPD of University teaching hospital (Majeedia hospital) New Delhi. Blood glucose levels and drug history of hypertensive patients were observed during four month of study.

Results: The gender distribution of hypertensive patients reveals a higher percentage of incidences in males (53\%) as compared to females (47\%). Hypertensive patient without diabetes mellitus (DM) on beta blockers shows higher incidence of impaired glucose tolerancse (IGT) $(13.3 \%)$ and DM (5\%) as compared to patient receiving ARBs as antihypertensive therapy. There was proportionate increase in incidence as the duration of therapy. None of the patients who were on angiotensin receptor blockers (ARBs) reported any incidence of IGT or DM.

Conclusion: Beta blockers may be the risk factor to develop diabetes mellitus type 2 on long term use as an antihypertensive therapy. There was no any incidence of impaired glucose tolerance or diabetes mellitus found in case of patients taking ARBs as an antihypertensive therapy so it can be safely prescribe in hypertensive patients associated with diabetes mellitus type 2 .

Key Words: Hypertension, Diabetes mellitus, impaired glucose tolerance, Beta blockers and ARBs.
\end{abstract}

\section{INTRODUCTION:}

There is highly prevalence of insulin resistance with hypertension, which is a major risk factor to develop type 2 diabetes mellitus ${ }^{1}$. Because hypertension and diabetes mellitus act as two big risk factors for cardiovascular disease, the risk gives a boost to increase when both synchronizes generally as part of metabolic syndrome. Data from trials of antihypertensive therapy commend that the risk of death, heart disease or stroke is around doubled in hypertensive diabetic patients with compared to those without hypertension ${ }^{2}$.

Most of the classes of antihypertensive drugs contrast with respect to their metabolic effects. For example, nonselective or $\beta 1$ - selective $\beta$-blockers drift to reduce insulin sensitivity, while angiotensin receptor-1blockers (ARBs) are tend to have beneficial effects on glycemic control. $\beta$ blockers have been revealed to potential appearance of new-onset type-2 DM in patients with hypertension ${ }^{3}$. Cessation of rennin angiotensin system, on other way, have been found to provide metabolic benefits by decreasing oxidative stress and recovering nitric oxide production, which may improve insulin sensitivity in patient with hypertension ${ }^{4}$.

It has been found in many trials that the incidence of new onset diabetes is incomparably deflate in patients treated with ARBs, ACE inhibitors 5.
In Indian population, there is no widely known studies on correlation between beta blockers and ARBs on blood glucose level. Therefore, the present study was planned to study the comparative effect of beta blockers and ARBs on blood glucose level among Indian population in South Delhi hospital.

\section{STUDY DESIGN AND METHODOLOGY}

2.1 The study was carried out in the OPD of Majeedia hospital, a 350 bed teaching hospital of Hamdard University, New Delhi. The protocol was approved by Jamia Hamdard Institutional Review Board (JHIRB) vide Approval Letter No. 02/10 dated 29 January 2010. It was a prospective study of beta-blockers and ARBs on blood glucose level in patients of hypertension without diabetes. All patients with established hypertension and those who were taking beta blocker and ARBs attending the Majeedia hospital were included in the study during the time period of February 2010 to June 2010.

2.2 Study population and assessed parameters: Study was carried out in 85 hypertensive patients without diabetes visiting to OPD in the department of medicine. The assessed parameters of study was; gender distribution, age distribution of subjects and blood glucose levels following chronic antihypertensive therapy. 
2.3 Inclusion and Exclusion Criteria: All patients with hypertension without diabetes, receiving antihypertensive therapy visiting the OPD of Medicine department, Majeedia Hospital were included in the study. Patients who were not treated with antihypertensive agents. Mentally challenged and unconscious, drug addicts, and those who unable to comply were contemplated as exclusion criteria.

2.4 Source of data: Physician's prescribing records, Patients' medication profile, and Pathology laboratory test reports. Patient's demographics (age, gender, weight, blood pressure levels, drug history, glucose levels, etc). Patients were interviewed after obtaining informed consent. Patients study proforma showing patient's demographics, drug history and pathology test reports.

2.5 Sample Collection: Blood samples of hypertensive patients for oral glucose tolerance test were collected by laboratory technician. The collected samples were sent to the in-house pathology lab and the reports were collected and interpreted by the investigators/clinician According to WHO 1999, fasting blood glucose level between 110 to $125 \mathrm{mg} / \mathrm{dl}$ and $2 \mathrm{hr}$ blood glucose level, after giving $75 \mathrm{gm}$ glucose through oral route in between 140-200 mg/dl were considered as impaired glucose tolerance. The patients were aforethought diabetic when the fasting blood glucose level was found to be more than $125 \mathrm{mg} / \mathrm{dl}$ and $2 \mathrm{hr}$ post prandial blood glucose was more than $200 \mathrm{mg} / \mathrm{dl}$.
2.6 Ethical Considerations: the study was based on the basic principles defined in US 21 CFR part 312.20 and ICH (09 May 1997) 'Guidance for Good Clinical Practice' and the principles enunciated in the Declaration of Helsinki (Edinburgh, October2000). The Protocol and the corresponding Informed Consent Form (ICF) were submitted to the Jamia Hamdard Institutional Review Board (IRB) for the approval of conduct of this study.

\section{OBSERVATION AND RESULT}

3.1 Gender assessment of subjects: 85 Patients were assessed to receive antihypertensive therapy during four month of study at Majeedia Hospital. Out of 85 patients $53 \%$ were male and $47 \%$ were female (Table 1).

Table 1: Gender distribution of subjects:

\begin{tabular}{|c|c|c|}
\hline Gender & No. of Patients & $\begin{array}{c}\text { Percentage of } \\
\text { Patients }\end{array}$ \\
\hline Male & 45 & 53 \\
\hline Female & 40 & 47 \\
\hline Total & 85 & 100 \\
\hline
\end{tabular}

3.2 Age dissemination of subjects: Hypertension was found more prevalent in patients of age group between 5160 years $(40 \%)$ followed by age group 41-50 (21\%) years. So prevalence of hypertension was more found between 40-60 years (Table 2).

Table 2: Age distribution of subjects:

\begin{tabular}{|r|c|c|c|c|c|c|}
\hline Age (yrs) & \multicolumn{1}{|l|}{ Male } & \% of male & Female & \% of female & Total & Total \% \\
\hline $20-30$ & 2 & 4.4 & 1 & 2.5 & 3 & 3.5 \\
\hline $31-40$ & 3 & 6.7 & 3 & 7.5 & 6 & 7 \\
\hline $41-50$ & 9 & 20 & 9 & 22.5 & 18 & 21 \\
\hline $51-60$ & 18 & 40 & 16 & 40 & 34 & 40 \\
\hline $61-70$ & 8 & 17.8 & 8 & 20 & 16 & 18 \\
\hline $71-80$ & 5 & 11.1 & 3 & 7.5 & 8 & 9.5 \\
\hline Total & 45 & 100 & 40 & 100 & 85 & 100 \\
\hline
\end{tabular}

Table 3: Blood glucose levels of patients receiving antihypertensive therapy.

\begin{tabular}{|l|l|l|l|l|l|l|l|l|}
\hline \multirow{2}{*}{$\begin{array}{l}\text { Category of } \\
\text { drug }\end{array}$} & First month & \multicolumn{2}{l|}{ Second month } & \multicolumn{2}{l|}{ Third month } & \multicolumn{2}{l|}{ Fourth month } \\
\cline { 2 - 8 } & FBG & PP & FBG & PP & FBG & PP & FBG & PP \\
\hline Beta- & 93.12 & 122.7 & 97.34 & $126.1 \pm 5.35$ & $111.1 \pm 8.11^{*}$ & $137.45 \pm$ & $117.37 \pm$ & $147.25 \pm$ \\
blockers & \pm 1.62 & \pm 1.28 & \pm 4.15 & & & $13.01^{*}$ & $6.8^{* *}$ & $12.43^{* *}$ \\
\hline ARBs & $92.5 \pm 0.81$ & $119.5 \pm$ & $94.3 \pm 1$ & $122.5 \pm 0.93$ & $93.14 \pm 1.1^{*}$ & $121.47 \pm 1.22^{*}$ & $96.31 \pm$ & $123 \pm$ \\
& & 1.3 & & & & & $1.11^{* *}$ & $3.4^{* *}$ \\
\hline
\end{tabular}

Values were represented as mean \pm SEM.

$F B G=$ Fasting blood glucose level; PP=Blood glucose level after two hours glucose. The data were significant by One way ANOVA followedby Tukey's Multiple Comparison Test.

$P<0.05$, statistically significant in case of Beta blockers vs ARBs.

$* p<0.05, * * p<0.01, * * *$ if $p<0.0001$,

3.3 Out of 85 hypertensive patients, 45 were prescribed beta blockers. Among beta blockers, atenolol was the most widely prescribed drug followed by metoporolol and carvedilol respectively. 40 patients were prescribed ARBs. Telmisartan is the most widely prescribed drug 
followed by Losartan Angiotensin receptor blockers (ARB).

3.4 Blood glucose levels of patients receiving beta blockers and ARBs:

Blood glucose level of patients taking beta blockers and ARB as antihypertensive therapy was observed during each month. It was found that beta blockers produce impairment in postprandial glycemic control in time dependent manner. It was found that disturbance in blood glucose level increase on prolong therapy of beta blockers. There was no any disturbance of blood glucose level was found as in case of ARB therapy. It was observed that beta blockers cause significant disturbance on blood glucose level as compare with ARBs (Table 3).

3.5 Total incidence of impaired glucose tolerance (IGT) or diabetes mellitus (DM)

During four month of study it was found that $13.3 \%$ incidence of impaired glucose tolerance and $5 \%$ incidence of diabetes mellitus was found in the group of patients who were using beta blockers as antihypertensive therapy. There was no any case of impaired glucose tolerance and Diabetes was found in group of patients who were using ARB as antihypertensive therapy (Table $4)$.

Table 4: Total incidence of IGT and DM in hypertensive patients

\begin{tabular}{|l|c|c|c|c|c|}
\hline $\begin{array}{c}\text { Drugs used as } \\
\text { antihypertensive therapy }\end{array}$ & $\begin{array}{c}\text { Number of } \\
\text { patients }\end{array}$ & $\begin{array}{c}\text { Incidence } \\
\text { of DM }\end{array}$ & $\begin{array}{c}\text { \% of Incidence } \\
\text { of DM }\end{array}$ & $\begin{array}{c}\text { Incidence of } \\
\text { IGT }\end{array}$ & $\begin{array}{c}\text { \% of } \\
\text { Incidence of IGT }\end{array}$ \\
\hline Beta blockers & 45 & 2 & $5 \%$ & 6 & 13.3 \\
\hline ARBs & 40 & 0 & $0 \%$ & 0 & 0 \\
\hline
\end{tabular}

\section{DISCUSSION}

Hypertension and diabetes are one of the most prevalent disease in worldwide. Diabetes mellitus and drug induced hyperglycemia is big issue in aspect of studies indicating that the therapy with different antihypertensive drug may have variant effect on blood glucose levels. It was believed that long term therapy influences these metabolic effects. Beta blockers and ARBs are the important drugs used in reduction of cardiovascular disease. Beta blockers may worsen glucose metabolism which may lead to Diabetes mellitus type 2 on long term treatment. ARBs may ameliorate insulin sensitivity in hypertensive patients ${ }^{6}$. Therefore it is big issue to monitor the metabolic consequences of antihypertensive drug so that potential adverse effect could be minimized. There is no such published study available to establish the relationship between beta blockers and ARBs on blood glucose level in hypertensive patients in Indian population.

The present study compares the effect of beta blockers and ARBs on blood glucose levels of Indian patients receiving antihypertensive therapy. The study was carried out in University Majeedia hospital at New Delhi. The observation was assessed on 85 patients during period of four months.

A higher percentage of male (53) as compared to (47) females was found on gender distribution of hypertensive patients. Patients who were prescribed beta blockes and ARBs In this study hypertensive patients were divided into two groups: those who were taking beta blocker and in other group who were using ARBs as antihypertensive therapy. Higher incidence of impaired glucose tolerance $(13.3 \%)$ and diabetes mellitus (5\%) was found in group of patients who were taking beta blockers as antihypertensive therapy. Thus the high blood glucose levels is a risk factor for onset of diabetes mellitus type 2 and it should be monitored properly when a patients is prescribing beta blockers.

No any incidence of impaired glucose tolerance or diabetes mellitus was observed in group of patients who were taking ARBs as antihypertensive therapy.Most of the literature supports this observation including the HOPE (Heart Outcomes Prevention Evaluation) trial, which indicate a reduced rate of new onset of diabetes mellitus in patients taking ARBs ${ }^{7-8}$.

Angiotensin receptor blockers may exert wholesome effects on glycemic control through a variety of mechanisms related to the inhibition of angiotensin $\mathrm{II}^{9-10}$. ARBs drug has been reported to activate insulin sensitizing peroxisome proliferator-activated receptor, gamma isotype pathways so it shows beneficial effect in glycemic control 11

In conclusion, beta blockers worsen the glycemic condition and may increase blood glucose level. It may be the risk factor to develop diabetes mellitus type 2 on long term use as an antihypertensive therapy. There was no any incidence of impaired glucose tolerance or diabetes mellitus found in case of patients taking ARBs as an antihypertensive therapy so it can be safely prescribe in hypertensive patients associated with diabetes mellitus type 2.

\section{ACKNOWLEDGMENT:}

The authors are highly thankful to Department of Pharmacology and Majeedia Hospital, Jamia Hamdard, New Delhi for providing facilties to do research work. 


\section{REFERENCES:}

1. Barzilay JI, Pressel S, Davis BR, Margolis KL, Cutler J, Ong ST, et al. Risk and impact of incident glucose disorder in hypertensive older adults treated with an ACE inhibitor, a diuretic, or a calcium channel blocker: a report from the ALLHAT trial. Am J Hypertens. 2004;17:1A-1A.

2. Curb JD, Pressel SL, Cutler JA, Savage PJ, Applegate WB, Black $\mathrm{H}$, et al. Effect of diuretic-based antihypertensive treatment on cardiovascular disease risk in older diabetic patients with isolated systolic hypertension. Systolic Hypertension in the Elderly Program Cooperative Research Group. $J$ Am Med Assoc. 1996;276:1886-92.

3. Elliott WJ, Meyer PM. Incident diabetes in clinical trials of antihypertensive drugs: a network meta-analysis. Lancet. 2007; 369: 201-07.

4. Siegel D, Swislocki AL Effects of Antihypertensives on glucose metabolism. Metabolic Syndrome and Related Disorders. 2007; 5(3):211-18.

5. Hansson L, Lindholm LH, Niskanen L, Lanke J, Hedner T, Niklason A, et al. Effect of angiotensinconverting-enzyme inhibition compared with conventional therapy on cardiovascular morbidity and mortality in hypertension: the Captopril Prevention Project (CAPPP) randomised trial. Lancet.1999;353:611-6.
6. Koh KK, Quon MJ, Han SH, Lee Y, Kim SJ, Koh Y et al. Distinct vascular and metabolic effects of different classes of anti-hypertensive drugs. International Journal of Cardiology. 2008;20: 30-8

7. Siegel D, Swislocki AL Effects of Antihypertensives on glucose metabolism. Metabolic Syndrome and Related Disorders. 2007; 5(3):211-18

8. Sowers JR, Bakris GL. Antihypertensive therapy and the risk of type 2 diabetes mellitus. N Engl J Med. 2000; 342:969-70.

9. Makita S, Abiko A, Naganuma Y, Moriai Y, Nakamura M. Effects of telmisartan on adiponectin levels and body weight in hypertensive patients with glucose intolerance. Metabolism Clinical and Experimental. 2008; 57: 1473-78.

10. Kurtz TW, Pravenec M. Antidiabetic mechanisms of angiotensinconverting enzyme inhibitors and angiotensin II receptor antagonists: beyond the reninangiotensin system. J Hypertension. 2004; 22:2253-2261.

11. Yusuf S, Teo K, Anderson C, Pogue J, Dyal L, Copland I. et al. Effects of the angiotensin-receptor blocker telmisartan on cardiovascular events in high-risk patients intolerant to angiotensin-converting enzyme inhibitors: a randomized controlled trial, Lancet. 2008; 372: 1174-83. 